\title{
Local production of bioethanol to meet the growing demands of a regional transport system
}

\author{
Lilia Daianova $^{1}$, Eva Thorin $^{1}$, Jinyue Yan $^{1,2}$, Erik Dotzauer ${ }^{1}$ \\ ${ }^{1}$ School of Sustainable Development of Society and Technology, Mälardalen University, Västerås, Sweden \\ ${ }^{2}$ Royal Institute of Technology, Stockholm, Sweden \\ * Corresponding author: Tel: +46 (0)21 1015 38, Fax: +46 (0)21 101480 \\ E-mail: lilia.daianova@mdh.se
}

\begin{abstract}
Energy security and the mitigation of greenhouse gas emissions (GHG) are the driving forces behind the development of renewable fuel sources worldwide. In Sweden, a relatively rapid development in bioethanol usage in transportation has been driven by the implementation of national taxation regulations on carbon neutral transport fuels. The demand for bioethanol to fuel transportation is growing and cannot be met through current domestic production alone. Lignocellulosic ethanol derived from agricultural crop residues may be a feasible alternative source of ethanol to secure a consistent regional fuel supply in Swedish climatic conditions. This paper analyzes how the regional energy system can contribute to reducing $\mathrm{CO}_{2}$ emissions by realizing local small scale bioethanol production and substituting petrol fuel with high blend ethanol mixtures for private road transport. The results show that about $13000 \mathrm{~m}^{3}$ of bioethanol can be produced from the straw available in the studied region and that this amount can meet the current regional ethanol fuel demand. Replacing the current demand for petrol fuel for passenger cars with ethanol fuel can potentially reduce $\mathrm{CO}_{2}$ emissions from transportation by $48 \%$.
\end{abstract}

Keywords: Agricultural crop residues, Straw, Bioethanol, Transport fuel, Greenhouse gas emissions (GHG)

\section{Introduction}

According to the EU Directive, the target share of renewable energy sources as a percentage of gross final energy consumption in Sweden in 2020 is 49\% [1]. Over the period 1990-2006 the proportion of renewable energy in final energy use has increased from $33.9 \%$ to $43.3 \%$. Renewable electricity generation and renewable energy from the industrial sector contribute most to the proportion of renewable energy in final energy use in Sweden today with $18 \%$ and $14 \%$ respectively. Renewable energy use in the transport sector accounts for less than $1 \%$ of the final energy use [2].

Road traffic dominates in domestic Swedish transportation and contributes 93\% of the total energy use in the transport sector (2009) [3]. Road transportation, which consists of private transport (mainly passenger cars), public transport and trucks, uses mostly fossil fuels, petrol and diesel. Use of renewable fuels such as ethanol, FAME (fatty acid methyl ester), biogas, and renewable electricity increased to $5.4 \%$ of the total energy use in transport by the end of 2009. Ethanol fuel made up 50\% of liquid biofuels used in 2009 [3]. In 2007-2008 the corresponding share of ethanol fuel was almost 60\% [4]. Along with a reduction in petrol fuel use in the last few years, ethanol use has also increased because almost all petrol is now a low blend E5 ethanol mixture. At the same time use of FAME and biogas increased by $8 \%$ and $1 \%$ respectively.

In Swedish transportation, the main current use of ethanol is as a 5\% additive to petrol fuel (E5) or as high blend ethanol mixtures (E85, ED95). According to data presented by [3], from 2003-2009 the share of E5 in petrol fuel in Sweden increased from 45\% to 95\%. Total ethanol use in the Swedish transport sector increased from about $150000 \mathrm{~m}^{3}$ in 2003 to $391000 \mathrm{~m}^{3}$ in 2009 [5]. The use of low blend ethanol fuel (E5) grew from $125000 \mathrm{~m}^{3}$ to $229000 \mathrm{~m}^{3}$, whereas the use of high blend ethanol fuels (E85, ED95) grew from $25000 \mathrm{~m}^{3}$ to $162000 \mathrm{~m}^{3}$ during the period 2003-2009 [5]. 
However, domestic commercial ethanol fuel production in 2009 was $221150 \mathrm{~m}^{3}$. Currently, bioethanol is produced by Lantmännen Agroetanol in Norrköping by fermentation of wheat grains with a capacity of $210000 \mathrm{~m}^{3}$, which almost meets the demand for low blend ethanol. SEKAB in Örnsköldsvik produces $16000 \mathrm{~m}^{3}$ ethanol from sugary liquor from sulphite pulp from Domsjö Factories, and the SEKAB pilot plant [6] produces $150 \mathrm{~m}^{3}$ ethanol from wood residues.

Ethanol demand in Sweden is much higher than domestic ethanol production. In the Swedish climate, cultivation of lignocellulosic biomass for bioethanol production is a possible alternative but there are still hurdles to overcome for the conversion of lignocelluloses to biomass. Consequently, realizing local small scale ethanol production can help regions to become more fossil fuel independent. This can also contribute to decreasing local environmental impact caused by transportation when replacing petrol fuel with renewable fuel. GHG emissions from road traffic totalled 29.1 million tonnes $\mathrm{CO}_{2}$ eq in 2006, 63.6 \% of the total Swedish transport sector emissions [7]. It is therefore of great importance to increase the use of biofuels in road transport, to make transport less dependent on fossil fuels and reduce GHG emissions.

GHG benefits of ethanol are discussed by Börjesson, where GHG emissions are estimated for the current Swedish grain-based ethanol production system [8]. Studies on technical performance of ethanol production integration with existing combined heat and power (CHP) plants have been published in recent years [9-11]. Models analysing road traffic energy demand and GHG emissions from transportation are developed for transport systems in China, Greece and Denmark [12, 13].

This paper focuses on analysing the potential for $\mathrm{CO}_{2}$ emissions savings by substituting petrol use in the region with ethanol fuel, and does not consider the details of ethanol production. Based on an analysis of straw supply, current and potential ethanol and petrol fuel demand, we evaluate the possibilities for a self-sufficient road transport fuel system.

The present paper addresses the following questions. What is the regional demand for bioethanol, in 2009 and in 2020? Is there sufficient cereal straw available for local ethanol fuel production in the studied region in 2009 and 2020? What proportion of $\mathrm{CO}_{2}$ emissions can be avoided in the region by substituting petrol use with ethanol fuel?

\section{Methodology}

In this study, input data is predominantly obtained from Swedish Official Statistics (SOS), which is also presented by state authorities (e.g. Swedish Energy Agency, Swedish Board of Agriculture) responsible for dissemination of statistical data in their respective areas. Input data collection is performed according to the structure shown in Figure 1.

The study region comprises the Sala-Heby municipalities, with around 35000 inhabitants and a total area of $2443 \mathrm{~km}^{2}$ [5]. They are typical small municipalities with a predominantly service oriented economy. There are also small scale and decreasing farming and production industries and some tourist activities. A large part of the working population commutes to larger cities outside of the study region. Sala and Heby are neighbouring municipalities that belong to different counties (Västmanland and Uppsala) and are situated about $100 \mathrm{~km}$ northwest of Stockholm. 


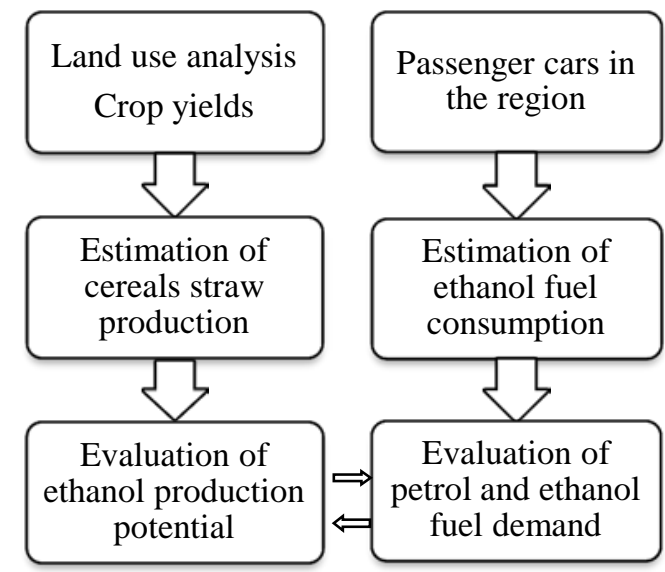

Fig. 1. A schematic flowchart for the local ethanol production study.

This paper focuses on analysing the potential for $\mathrm{CO}_{2}$ emissions savings in the region by substituting petrol with ethanol fuel in transportation, ignoring the technological aspects of local small scale bioethanol production. The input year of the analysis is 2009. As cereal straw is considered as a feedstock for ethanol production in this study, all estimates are made for straw-based ethanol replacing regional petrol fuel demand. The study only considers fuel use by passenger cars as this is the dominant form of transport in regional road traffic.

In the Sala-Heby region, a total of 25 buses that run on diesel and biogas are used in public transportation. In Sala, the local public transportation company, Västmanlands Lokaltrafik, plans to substitute at least 10 of its 12 buses for biogas fuelled buses by 2014 [14]. In Heby, all 13 buses run on diesel and will be substituted with biogas buses during 2011-2012 according to the company's plan [15]. Buses are therefore excluded from the current analysis as none of the buses currently run on ethanol fuel and there are no plans for them to do so in future. Data on bus transportation in municipalities is obtained from local collective transportation companies as official statistical databases only present data on a regional level.

\subsection{Data and assumptions}

\subsubsection{Straw supply and ethanol production potential}

Input data is obtained from official statistics databases presented by the Swedish Board of Agriculture [16]. In this study, straw from wheat, barley and oats are considered as a feedstock for ethanol production as these types of cereals are the most commonly cultivated in the region. These cereals made up nearly $97 \%$ of the total cultivation area for cereals in the region in 2009 [16].

The ethanol production potential in the region (B) is calculated for each cereal type (wheat, oats and barley) using Eq. (1):

$B=\sum_{i=1}^{4} S_{i} Y_{i} R_{i} A Y_{\text {EIOH }}$

where $B$ is straw-based ethanol production potential (MWh), $S_{i}$ is the cereals cultivation area (ha), $Y_{i}$ is the cereals yield in the respective county ( $\left.\mathrm{kg} / \mathrm{ha}\right), R_{i}$ is the crop to residue ratio for each cereal type, $A$ is the straw availability, $Y_{E t O H}$ is the ethanol production yield from straw (litre/kg), and $i$ is the type of cereal crop. 
Input data for estimation of straw supply and ethanol production potential is presented in Table 1 and in the text below.

Table 1. Input data for straw supply in the Sala-Heby region, 2009.

\begin{tabular}{|c|c|c|c|c|c|c|}
\hline \multirow[t]{2}{*}{ Parameter } & \multirow[t]{2}{*}{ Unit } & \multicolumn{4}{|c|}{ Type of biomass } & \multirow[t]{2}{*}{ Reference } \\
\hline & & $\begin{array}{l}\text { winter } \\
\text { wheat }\end{array}$ & $\begin{array}{l}\text { spring } \\
\text { wheat }\end{array}$ & barley & oats & \\
\hline $\mathbf{R}_{\mathbf{i}}$ & 1 & 1.3 & 1.3 & 1.2 & 1.3 & {$[17]$} \\
\hline $\mathrm{C}_{\mathrm{i}}$ & tonnes/year & 14733 & 12464 & 41137 & 30549 & Based on data from $[5,15]$ \\
\hline
\end{tabular}

* Cereals production, $\mathrm{C}_{\mathrm{i}}=\mathrm{S}_{\mathrm{i}} * \mathrm{Y}_{\mathrm{i}}$

Cereals production $\left(\mathrm{C}_{\mathrm{i}}\right)$ is calculated based on cultivation areas and average yields for cereal crop production. Cereal yields $\left(\mathrm{Y}_{\mathrm{i}}\right)$ for Sala and Heby municipalities correspond to average yields in the counties that the municipalities belong to. As a proportion of straw has to be ploughed back into the soil to maintain the soil fertility and avoid erosion, only about $57 \%$ by weight (A in Eq. 1) of the total amount of straw produced can be used for fuel production [17]. The energy content of pure ethanol is $6.24 \mathrm{kWh} /$ litre [18].

The future straw supply in the region is analyzed for the following scenarios:

- Scenario 2020-P1 - all the parameter values remain the same except areas for cereals cultivation. The total straw production is assumed to increase by $20 \%$ through use of fallow land for ethanol straw cultivation. Fallow land currently accounts for $29 \%$ of arable land for cereals production in the Sala-Heby region.

- Scenario 2020-P2 - all the parameter values remain the same except the yield for ethanol conversion from straw, which is assumed to increase to 0.35 (litre/kg) $\left(\mathrm{Y}_{\mathrm{EtOH}}\right)$ due to improvements in the process technology.

- $\quad$ Scenario 2020-P3 - combines scenarios 2020-P1 and 2020-P2.

\subsubsection{Transport fuel demand}

There is a lack of statistics on motor fuel usage at the municipal level. We calculate the average distance covered per car and average fuel consumption per kilometre driven, and therefore the use of motor fuel based on the number of passenger cars registered in the municipalities of Sala and Heby. Input data was obtained from Swedish Official Statistics [5, 19]. The Swedish Energy Agency is the state authority responsible for disseminating statistics in the field of energy use in transportation, and Transport Analysis (Trafa) produces statistics on vehicles types and distances covered. The development of passenger car use in Sala-Heby region is shown in Figure 2 (based on data from [19]).

Ethanol fuel demand in the Sala-Heby region (D) is estimated for E5 and E85 ethanol mixtures using Eq. (2):

$D=\sum_{i=1}^{2} N_{i} S_{i} Q_{i} C_{i} E$

where $D$ is estimated ethanol fuel demand (MWh), $N_{i}$ is the number of vehicles in use during a year, $S_{i}$ is the distance covered per vehicle in the respective county in a year $(\mathrm{km}), Q_{i}$ is the fuel consumption per type of fuel and kilometre driven in each county (litre/km), $C_{i}$ is the ration of pure ethanol to petrol in each type of fuel blend used, and $E$ is the energy content of the fuel (kWh/litre). For E5 fuelled passenger cars $\mathrm{i}=1$, and for E85 fuelled passenger cars $\mathrm{i}=2$. 


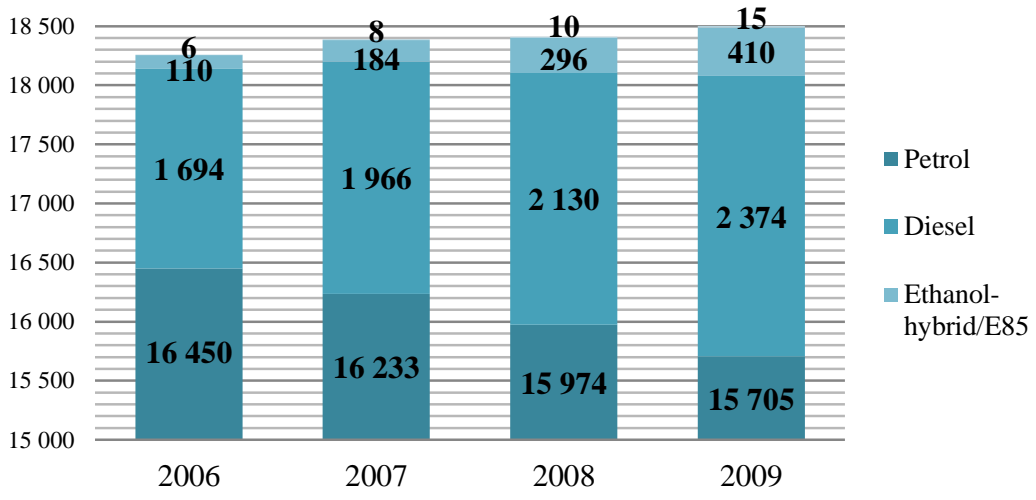

Fig. 2. Passenger cars in use by fuel type in 2006 -2009 in Sala-Heby. Based on data from [19].

It is assumed that all petrol fuel in the region is E5 fuel, as the share of low blend petrol in Sweden is 95\% according to [3] and more detailed data on the regional share of E5 fuel and petrol fuel is not available.

To evaluate current and future regional demand on transport the following scenarios were analyzed:

- Scenario 2020-D1 - all the parameters remain the same except the numbers of passenger cars fuelled by petrol and ethanol fuels. The number of E85 fuelled cars increases and the number of E5 fuelled cars decreases, following the same trend as during the period 20062009 for each vehicle type. In this way, the total number of E5 and E85 fuelled vehicles is projected to be 17814 , a reasonable increase of $10.5 \%$ the 2009 figure.

- Scenario 2020-D2 - all the parameters remain the same except the amount of ethanol blended with petrol fuel, which is assumed to increase from $5 \%$ to $10 \%$ of the petrol fuel mixture, meaning that passenger cars are fuelled E10 with instead of E5. As in scenario 2020_1, the total number of cars is 17 814, following the trend in car numbers for the period 2006-2009. Petrol fuel consumption per driven kilometre is assumed to decrease following the trend from 2006-2009 (-1.2\%), and is $0.074 \mathrm{l} / \mathrm{km}$ in 2020.

- Scenario 2020-D3 - this is the most extreme scenario, where it is assumed that all passenger cars are to be fuelled by E85 ethanol fuel.

\subsection{3. $\mathrm{CO}_{2}$ emissions from transportation}

Estimates of $\mathrm{CO}_{2}$ eq. emissions from passenger cars are based on the results presented by Johansson and Fahlberg [18]. Emissions rates in [18] and those presented in Table 2 are lifecycle based and include emissions from fuel combustion, production and distribution. The $\mathrm{CO}_{2}$ eq. emissions factors on which further calculations are based are presented for E5, E85 and E10 (see Table 2).

Table 2. Total $\mathrm{CO}_{2}$ eq. emissions factors by type of transport fuel [18].

\begin{tabular}{lr}
\hline $\mathrm{CO}_{2}$ eq. emissions by type of fuel, $(\mathrm{g} / \mathrm{kWh})$ \\
\hline E5 & 277.48 \\
E10 & 269.34 \\
E85 & 110.54 \\
\hline
\end{tabular}




\section{Results and discussion}

Regional straw production is estimated using Eq 1 and the input data presented in section 2.1.1. This calculation estimates 98924 tonnes of straw in 2009. Thus, current straw-based ethanol production potential in Sala-Heby is $13015 \mathrm{~m}^{3}$ or 81210 MWh as presented in Table 3 for 2009 and future Scenarios.

Table 3. Estimate of straw based ethanol production in Sala-Heby region.

\begin{tabular}{cccccc}
\hline Parameter & Unit & 2009 & $2020-\mathrm{P} 1$ & $2020-\mathrm{P} 2$ & $2020-\mathrm{P} 3$ \\
\hline $\mathrm{B}_{\text {ethanol }}$ & MWh/year & 81210 & 97452 & 98012 & 117615 \\
\hline
\end{tabular}

Regional ethanol fuel demand is estimated using Eq. 2 and the assumptions from the scenarios presented in section 2.1.2., and is presented in Table 4.

Table 4. Estimate of ethanol fuel demand in Sala-Heby region. Parameters for year 2009 are input parameters obtained from statistical databases and reports. Values in bold are changed from 2009.

\begin{tabular}{ccccccc}
\hline Parameter & Unit & 2009 & 2020-D1 & 2020-D2 & 2020-D3 & $\begin{array}{c}\text { Referen } \\
\text { ce }\end{array}$ \\
\hline $\mathrm{N}_{1}$ & 1 & 15705 & $\mathbf{1 3 ~ 2 5 1 *}$ & 13251 & $\mathbf{0}$ & {$[19]$} \\
$\mathrm{N}_{2}$ & 1 & 410 & $\mathbf{4} \mathbf{5 6 3} * \boldsymbol{*}$ & 4563 & $\mathbf{1 7 ~ 8 1 4}$ & {$[19]$} \\
$\mathrm{S}_{1}$ & $\mathrm{~km}$ & 14267 & 14267 & 14267 & 14267 & {$[19]$} \\
$\mathrm{S}_{2}$ & $\mathrm{~km}$ & 14267 & 14267 & 14267 & 14267 & {$[19]$} \\
$\mathrm{Q}_{1}$ & $\mathrm{l} / \mathrm{km}$ & 0.084 & 0.084 & $\mathbf{0 . 0 7 4}$ & not relevant & \\
$\mathrm{Q}_{2}$ & $\mathrm{l} / \mathrm{km}$ & 0.126 & 0.126 & 0.126 & 0.126 & {$[18]$} \\
$\mathrm{C}_{1}$ & 1 & 0.05 & 0.05 & $\mathbf{0 . 1}$ & not relevant & \\
$\mathrm{C}_{2}$ & 1 & 0.85 & 0.85 & 0.85 & 0.85 & \\
$\mathrm{E}_{1}$ & $\mathrm{kWh} /$ litre & 8.598 & 8.598 & 8.474 & 8.598 & {$[18]$} \\
$\mathrm{E}_{2}$ & $\mathrm{kWh} /$ litre & 6.612 & 6.612 & 6.612 & 6.612 & {$[18]$} \\
$\mathrm{D}_{\text {ethanol }}$ & $\mathrm{MWh} /$ year & 12234 & 52927 & 57955 & 179977 & - \\
\hline
\end{tabular}

*Average annual decrease in petrol fuelled passenger cars is $1.5 \%$. Based on this rate the number of E5 fuelled passenger cars is estimated at 13251.

**Average annual increase in E85 fuelled cars during 2006-2009 is 39\%, whereas assumed average increase after 2014 is $20 \%$. It is assumed to be unlikely that the early increase of $39 \%$ is maintained until 2020.

Distance covered per car and year for the whole Sala-Heby region is calculated from weighted averages of distances covered per car and year in each municipality. Distances covered by car in each municipality are obtained from [19] and are assumed to remain the same over the study period. Fuel consumption per driven $\mathrm{km}$ is assumed to decrease following the same trend as 2006-2009. E85 fuel consumption $\left(\mathrm{Q}_{2}\right)$ is assumed to remain the same. In scenario 2020-D2 E10 fuel is assumed to be used $\left(C_{1}=0.1\right)$. For Scenario 2020-D2, the energy content of the fuel $\left(E_{1}\right)$ corresponds to the energy content of the E10 ethanol mixture based on the assumption made for this scenario.

Summarized results for straw based ethanol supply and ethanol demand are presented in Figure 3. These figures indicate that the regional transport system can become self-sufficient in ethanol fuel by implementing local small ethanol production from locally produced cereal straw. The system could become fossil fuel free by 2020 using this approach. 


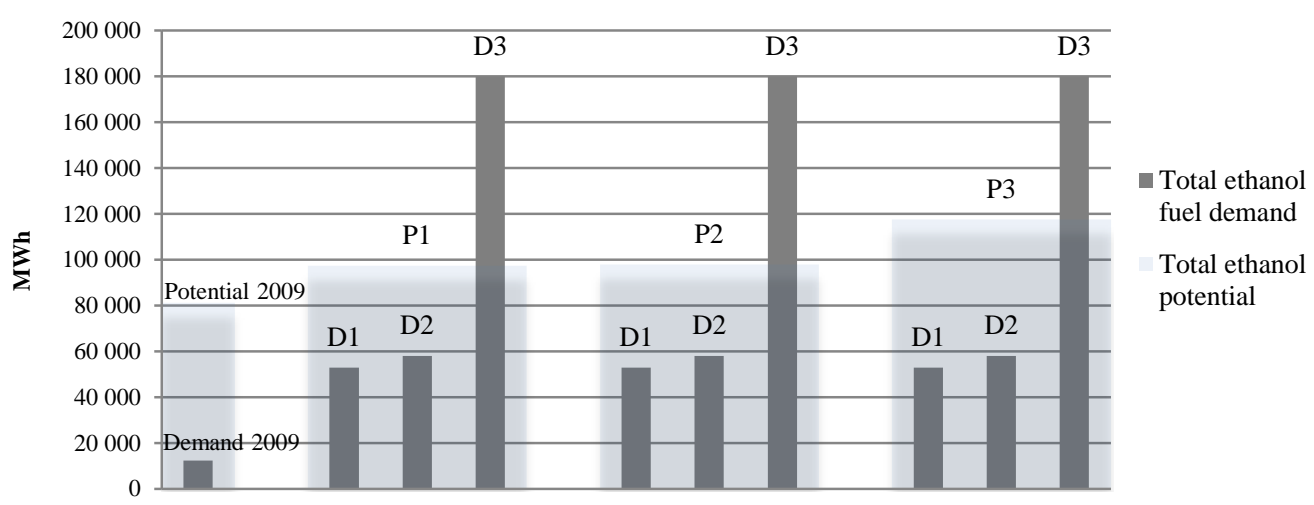

Fig.3. Ethanol supply potential and ethanol fuel demand in the Sala-Heby region (MWh).

The $\mathrm{CO}_{2}$ eq. emissions from passenger cars were estimated (see Table 5), based on the same scenarios and approach as for the estimate of the ethanol fuel demand (see section 2.1.2.). Current $\mathrm{CO}_{2}$ eq. emissions from transport are 45446 tonnes. Assuming that the number of passenger cars in the region continues to increase according to the trend of the last 5 years, and assuming that all cars will run on E85 in 2020, the total $\mathrm{CO}_{2}$ eq. emissions can be reduced to 23591 tonnes $\mathrm{CO}_{2}$ eq., a reduction of 21855 tonnes $\mathrm{CO}_{2}$ eq. or $48 \%$ from 2009 .

Table 5. Estimate of $\mathrm{CO}_{2}$ eq. emissions from passenger cars in Sala-Heby region.

\begin{tabular}{ccccc}
\hline Parameter & 2009 & $2020-\mathrm{D} 1$ & $2020-\mathrm{D} 2$ & 2020-D3 \\
\hline $\begin{array}{l}\text { Total } \mathrm{CO}_{2} \text { emission from passenger cars } \\
\text { fuelled by petrol and ethanol fuel, tonnes }\end{array}$ & 45446 & 43930 & 38938 & 23591 \\
\hline
\end{tabular}

Börjesson [8] studied the reduction of GHG emissions obtained from using ethanol instead of petrol, including GHG emissions from producing ethanol. Using wheat grain based ethanol produced in Sweden results in an 80\% GHG emission reduction compared to petrol fuel, while ethanol from Brazilian sugarcane gives 85\% emission reduction [8]. Börjesson concluded that the results are very much dependent on the structure of the individual system. Assuming some different scenarios for the type of cultivation land, use of by-products from ethanol production, the reduction of using ethanol from current production in Sweden can be as low as 55\% [8]. This paper focuses on GHG emission savings from road private traffic if replacing current petrol use with locally produced straw based ethanol assuming different scenarios for future car fleet development and ethanol supply. The CO2 eq. emission factors presented in [18], on which the calculations in this paper are based, correspond to $76 \%$ total $\mathrm{CO} 2$ eq. emission savings for pure ethanol compared with pure petrol fuel.

\section{Conclusions}

This study shows that the available cereal straw in the studied region is sufficient to meet local ethanol demand for 2009. However, it is not sufficient for a scenario where all passenger cars are fuelled with E85. If passenger car numbers increase according to the current trend until 2020,3\% $\mathrm{CO}_{2}$ eq. emissions reductions can be achieved by using locally produced ethanol from cereal straw. $\mathrm{CO}_{2}$ eq. emissions can be reduced by $14 \%$ by replacing all petrol fuel with fuel containing 10\% ethanol (E10 fuel), and by $48 \%$ if all passenger cars in the studied region use E85 fuel.

This paper analyzes how the regional energy system can contribute to reducing $\mathrm{CO}_{2}$ eq. emissions by realizing local small scale bioethanol production and substituting petrol with ethanol fuels in road transportation. 


\section{References}

[1] Directive 2009/28/EC of the European Parliament and the Council of 23 April 2009 on the promotion of the use of renewable sources and amending and subsequently repealing Directives 2001/77/EC and 2003/30/EC

[2] Energy Indicators 2008. Theme Renewable Energy, Swedish Energy Agency, Report ET2008:21, Västerås, 2008, 97 pp.

[3] Energy Use in Transport Sector - 2009, Swedish Energy Agency, Report ES2010:04, Eskilstuna, 2010, 28 pp.

[4] Energy Use in Transport Sector - 2008, Swedish Energy Agency, Report ES2009:04, Eskilstuna, 2009, 24 pp.

[5] Statistics Sweden (SCB), 2010 - http://www.ssd.scb.se/databaser/makro/start.asp

[6] Swedish Energy Agency, Report ER 200927 (in Swedish), “Kvotpliktsystem för biodrivmedel - Energimyndighetens förslag till utformning”, Eskilstuna, 2009

[7] European Environment Agency (EEA), October 2008

[8] Börjesson P., Good or bad bioethanol from a greenhouse gas perspective - What determines this?, Applied Energy, Vol. 86, Issue 5, pp. 589-594, 2009

[9] Starfelt, F., Thorin, E., Dotzauer, E., Yan, J. Performance evaluation of adding ethanol production into an existing combined heat and power plant, Bioresource Technology, 101 (2010) pp. 613-618

[10]A. Wingren, M. Galbe and G. Zacchi, Energy considerations for a SSF-based softwood ethanol plant, Bioresource Technology, 99 (2007), pp. 2121-2131

[11] Seabra, J., Tao, L., Chuma, H.L., Macedo, I. C. A techno-economic evaluation of the effects of centralized cellulosic ethanol and co-products refinery options with sugarcane mill clustering, Biomass and Bioenergy, 34 (2010), pp. 1065-1078

[12]Ou, X., Zhang, X., Chang, S. Scenario analysis on alternative fuel/vehicle for China's future road transport: Life-cycle energy demand and GHG emissions, Energy Policy, 38 (2010), pp. 3943-3956

[13] Papagiannaki, K., Diakoulaki, D., Decomposition analysis of $\mathrm{CO}_{2}$ emissions from passenger cars: The cases of Greece and Denmark, Energy Policy, 37 (2009), pp. 32593267

[14]Upplands lokaltrafik, personal communication, 2010

[15] Västmanlands lokaltrafik, personal communication, 2010

[16] Swedish Board of Agriculture, 2010 - http://statistik.sjv.se/

[17] Johansson, J., and Lundqvist, U. Estimating Swedish biomass energy supply. Biomass and bioenergy, 1999; 17(2): 85-93

[18] Johansson, S., Fahlberg, K., 2009, Methods for strategies and assessment of climate change mitigation initiatives at local and regional levels, Emission Factors - Statistical Datasheet, http://www.ima.kth.se/klimatswe/html/rapporter.htm

[19] Transport Analysis, Trafa, 2010 - http://www.trafa.se/Publikationer/ 